\title{
Genetics and global healthcare
}

\author{
AH Bittles \\ Adjunct Professor and Research Leader, Centre for Comparative Genomics, Murdoch University and Adjunct Professor of Community \\ Genetics, School of Medical Sciences, Edith Cowan University, Perth, Australia
}

ABSTRACT During the course of the last decade there has been extensive discussion on the role of genetics and genomics in global healthcare, with major diagnostic advances regularly announced, such as exome sequencing to identify and classify de novo, autosomal and X-linked mutations in people with severe intellectual disability, and whole-genome sequencing for prenatal diagnosis of chromosomal anomalies, ${ }^{2}$ in the differential diagnosis of acute neonatal disorders, ${ }^{3}$ and in devising improved treatment protocols. ${ }^{4}$ There are, however, a number of basic issues that need to be addressed if advances of this nature are to be more widely translated in terms of healthcare.

KEYWORDS: Genetics, genomics, burden of disease, rare diseases, disease registries

DECLARATION OF INTERESTS Professor Bittles was an Expert Panel member for the Global Burden of Disease Study 2010. He is an Expert Panel member of Grand Challenges in Genomics for Public Health in Developing Countries and a Co-investigator in the EU Framework 7 Programme RD-Connect.
Correspondence to AH Bittles Centre for Comparative Genomics Murdoch University

South Street

Perth WA 6150

Australia

\section{tel. +61893606088}

e-mail

abittles@ccg.murdoch.edu.au

\section{OUTDATED AND INADEQUATE DISEASE PREVALENCE DATA}

First and foremost, reliable and representative data on the prevalence and distribution patterns of inherited disorders are currently lacking at global, regional, country and community levels, and phenotypic heterogeneity in more rare disorders often goes undocumented. An innovative and determined attempt to fill this void was made in the 2006 March of Dimes Global Report on Birth Defects, based on the summary statistic that $6 \%$ of children (7.9 million) are born annually with a serious birth defect of genetic or partially genetic origin, $90 \%$ of whom are resident in low or middle income countries (LMIC). ${ }^{5}$ However the report was critically dependent on the available literature, and by providing annual disease estimates precise to a single integer, e.g. with glucose 6-phosphate dehydrogenase deficiency estimated in 177,032 births worldwide, it conveyed a questionable sense of security in the accuracy and completeness of the data collected.

There has also been a failure to acknowledge that in many LMIC the population is sub-divided into multiple ethnic, religious, language and social groups within which individuals live, marry and reproduce. The net result is that co-resident communities commonly exhibit markedly different inherited disease profiles and prevalences. For example, in India a widely cited estimate is that $3-4 \%$ of the population are carriers of $\beta$-thalassaemia, ${ }^{6}$ with five mutations IVSI-5 (G>C), IVSI-I (G>T), 619-bp del, Codon 4l/42 (-TCTT) and Codon $8 / 9(+\mathrm{G})$, accounting for $90 \%$ of all cases. However, these data were very largely based on the populations of just three of the 35 states and Union territories of India, Gujarat, Punjab and Maharashtra, with significantly different $\beta$-thalassaemia mutation profiles observed in other regions of the country. ${ }^{7}$ Further, and perhaps of greater significance from a genetic epidemiology perspective, carrier rates for $\beta$-thalassaemia ranged from $0 \%$ to $9.3 \%$ in different ethnic groups. ${ }^{8}$ Which raises a major query as to the practical value of a national disease prevalence estimate in a genetically and socially heterogeneous country of approximately 1.3 billion people and comprising over 50,000 endogamous communities. The issue of population stratification is not restricted to large countries such as India with, for example, significant genetic sub-divisions clearly identified in Iceland with a population of just $320,000 .^{9}$

\section{PROBLEMS ENGENDERED BY INADEQUATE HEALTH DATA}

Difficulties that can arise because of the paucity of reliable prevalence data on genetic disorders influenced The Global Burden of Disease Study 2010 (GBD 2010), ${ }^{10}$ launched in The Royal Society, London in 2012, with the findings presented in The Lancet." The 291 major diseases and injuries examined were collated into 67 groups of risk factors and hundreds of sub-categories. The specific genetic disorders included in GBD 2010 were haemoglobinopathies and haemolytic anaemias, which were listed in the sub-category 'diabetes, urogenital, blood, and endocrine diseases', and congenital anomalies, listed under 'other non-communicable diseases'. It is therefore no great surprise that in comparison with the five leading risk factors identified as causing poor health: high blood pressure, tobacco use (excluding second- 
hand smoke), alcohol use, household air pollution from solid fuels, and a diet low in fruits, genetic disorders did not feature prominently in terms of the overall global health burden, or in health metrics such as years lived with disability (YLDs). ${ }^{12}$

Interestingly, the Director General of the World Health Organization (WHO) drew attention to the fact that in a number of areas the results of GBD 2010 differed substantially from analyses by WHO and other United Nations entities, and indicated her intention both to improve data on global health and to close data gaps which especially impact on the populations of LMIC. ${ }^{13} \mathrm{To}$ some extent these deficiencies may be ameliorated in a current WHO initiative: Grand Challenges in Genomics for Public Health in Developing Countries, ${ }^{14}$ with the findings and ranked recommendations scheduled for presentation in 2013. But once again the data on which the recommendations of expert panel members are based will be seriously incomplete, necessitating reliance on statistical inferences being drawn from data sets of approximate comparability. And in most LMIC it is the least advantaged sections of the population who will continue to be significantly under-represented in disease statistics.

The recent re-ordering of research priorities towards studies based on rare diseases may assist in focusing more appropriate attention on genetic disorders. Within Europe rare diseases are defined as disorders that individually affect fewer than 5/10,000 people. But according to EUROCAT, the organisation responsible for the surveillance of congenital anomalies in Europe, ${ }^{15}$ collectively they account for a significant proportion of the overall burden of disease, with some $6-8 \%$ of the European Union (EU) population expressing one or more of 5,000 to 8,000 rare diseases, i.e. between 27 and 36 million people. Detailed information on these rare diseases is listed on the Orphanet portal. ${ }^{16}$

It will be some time before equivalently representative data are available for most LMIC. However, the recently funded EU Framework 7 programme RD-Connect, with 25 EU, North American and Australian collaborating centres, may help to close this gap (http://rd-connect.eu). RD-Connect is planned as an integrated platform connecting patient registries, biobanks and clinical bioinformatics for research into rare diseases. The practical importance of disease registries in a LMIC has been demonstrated for $\beta$-thalassaemia in India, where the registry Thallnd is a nationally available resource, with internet access permitting secure data entry even for subjects resident in rural and remote regions and improved patient management by local health practitioners. ${ }^{17}$ More generally, a customisable modular disease registry framework that offers secure multi-level access and interoperability with other data systems has been designed for a range of rare diseases. ${ }^{18}$

\section{ADDRESSING THE SHORTAGE OF TRAINED PERSONNEL AND FACILITIES}

Lack of formal training in genetics for clinicians and other healthcare professionals in LMIC has led to ongoing problems with diagnosis and in patient care. This shortcoming exists even in richer regions, such as the Middle East, and to date attempts to effect significant improvements have met with only limited success. ${ }^{19}$ The situation is exacerbated by poor public knowledge of genetics, and a consequent lack of understanding of how or why certain diseases are transmitted within families and communities. ${ }^{20}$ This difficulty also exists in high income countries, an ongoing example being the controversy surrounding cousin marriage in the UK Pakistani community, which has been affected by illadvised public interventions by politicians and others..$^{20,21}$

Increased numbers of clinical geneticists are essential to facilitate progress, and trained genetic counsellors, genetic nurses, and medical laboratory scientists are also needed to provide requisite levels of diagnostic skills and patient care. The requirement for suitably skilled and experienced staff is especially acute in the many countries where major population sub-divisions exist, with strict community endogamy and very often a traditional preference for close kin marriage..$^{20}$ Under these circumstances the expression of rare or even unique founder mutations becomes more probable, and in numerically small populations genetic drift also can play a significant role, as exemplified by the 'Finnish disease heritage'. ${ }^{20}$

Unfortunately, in many countries the trained personnel needed to provide a fully fledged clinical genetics service simply may not be available, and/or their appointment is not feasible within the scope of the national or local budget. The low priority ranking of genetic disorders in programmes such as GBD 2010 also may deter governments from investing in genetic services, with preference given to issues perceived to be of greater importance from a public health perspective. Brazil exemplifies several of these problems but the country's health planners have also devised various means for their partial solution. As an example, the Community Health Agents (CHA) Programme was established in I99I as part of the national healthcare scheme (Sistema Único de Saúde). Community Health Agents have a minimum of eight years of education and since they are recruited from local communities they are conversant with local health issues. Given the small numbers of clinical geneticists in Brazil, and in the absence of a formal career structure for genetic counsellors, the assistance of CHAs has proved to be invaluable in the early identification and follow-up of individuals and families with rare inherited disorders. ${ }^{22}$ At least as a short- to mediumterm measure, the CHA system offers a model that could productively be adopted by other LMIC, particularly in geographically more remote regions. 


\section{DISEASE REGISTRIES AND NATIONAL, REGIONAL AND INTERNATIONAL COLLABORATIONS}

Registries for specific disorders within the UK have enabled areas of high disease prevalence to be identified, which is increasingly important given the multi-ethnic nature of the population. As previously noted, EUROCAT provides a similar, highly regarded service within the EU by collating and analysing data on congenital disorders in the approximately I.7 million births delivered per year. Equivalent regional databases for genetic disorders include Estudio Colaborativo Latino Americano de Malformaciones Congenitas (ECLAMC), ${ }^{23}$ established in 1967 and now covering maternity hospitals in all 12 countries of South America plus Costa Rica and the Dominican Republic, and the Catalogue of Transmission Genetics in Arabs, which is maintained by the Centre for Arab Genomic Studies (CAGS) and analyses data from 23 countries in the Middle East and North Africa. ${ }^{24}$ Each of these regional bodies additionally is a contributing member of the WHO Collaborating Centre for the Surveillance of Congenital Anomalies. ${ }^{25}$

Internet-based communication and mobile telephony are substantially easing the difficulties faced in providing healthcare and advice to rural and remote communities. However, rather than these facilities simply being restricted to national or regional populations, they also can benefit from North-South collaborations. In particular since most clinical geneticists in the UK and other western countries now have extensive experience in the diagnosis and treatment of patients with nonEuropean ancestries. An example of this type of synergistic North-South cooperation is the recently

\section{REFERENCES}

I de Ligt J, Willemsen $\mathrm{MH}$, van Bon BW et al. Diagnostic exome sequencing in persons with severe intellectual disability. New Engl JMed 20 I 2;367: I 92 I-9.http://dx.doi.org/I0.I056/NEJMoa I 206524

2 Talkowski ME, Ordulu Z, Pillalamarri V et al. Clinical diagnosis by whole-genome sequencing of a prenatal sample. New Engl J Med 2012; 367:2226-32. http://dx.doi.org/ I0.I056/NEJMoa I 208594

3 Saunders CJ, Miller NA, Soden SE et al. Rapid whole-genome sequencing for genetic disease diagnosis in neonatal intensive care units. Sci Transl Med 20I2; 4:I54ra I 35.

4 Bainbridge MN,Wiszniewski W, Murdock DR et al.Whole-genome sequencing for optimized patient management. SciTransl Med 20 I ; 3:87re3.

5 Christianson A, Howson CP, Modell B. March of Dimes global report on birth defects [Internet].White Plains, New York: March of Dimes Birth Defects Foundation; 2006 [cited 2013 Jan I7].Available from: http://passthrough.fw-notify.net/download/032457/http://www. marchofdimes.com/downloads/birth_defects_report-pf.pdf

6 World Health Organization. Management of haemoglobin disorders [Internet]. Geneva:WHO; 2008 [cited 2013 Jan 17].Available from: http://www.who.int/genomics/WHO-TIF_genetics_final.pdf

7 Sinha S, Black ML, Agarwal S et al. Profiling $\beta$-thalassaemia mutations in India at state and regional levels: implications for genetic education, screening and counselling programmes. Hugo $\mathrm{J}$ 2009; 3:5 I-62. http://dx.doi.org/I0.1007/s I I568-0 I0-9/32-3 established Action on Birth Defects programme in the mainly rural state of Uttarakhand in northern India, where inputs from experienced health practitioners from other Indian states, the Public Health Genomics Foundation in Cambridge, UK and the Centre for Comparative Genomics in Murdoch University, Australia have been integrated with local expertise to formulate a public health strategy for congenital disorders.

\section{TOWARDS A BRAVE NEW FUTURE}

Since the completion of the Human Genome Project a decade ago the initially underestimated complexity of genetic disease and its impact on human health has become increasingly obvious. The role of microRNAs, epigenetic control of gene expression, the heterogeneity of many inherited diseases, and the as-yet 'missing' information on the heritability of common complex disorders $^{26}$ all require solution. For the populations of high income countries, personal genome sequencing is increasingly accessible as a means of providing differential diagnoses of genetic disorders and in identifying individualised therapies. ${ }^{27}$ The picture is markedly different for a large majority of those living in LMIC, with inadequate data, a lack of trained personnel, restricted diagnostic facilities, and cost constraints retarding progress. But even in these countries significant advances are being made, and the increasing affordability of genomic analysis combined with internet-based bioinformatics systems and comprehensive disease registries suggest that this process can and will accelerate within the present decade, allowing a better life for those with genetic disorders and offering renewed hope to their families and communities.

8 Mohanty D, Colah RB, Gorakshakar AC et al. Prevalence of $\beta$-thalassemia and other haemoglobinopathies in six cities in India: a multicentre study.J Community Genet 20 I 2; 4:33-42. http://dx.doi. org/I0.1007/s I 2687-0 I2-0 I |4-0

9 Helgason A, Yngvadóttir B, Hrafnkelsson B et al. An Icelandic example of the impact of population structure on association studies. Nat Genet 2005; 37:90-5.

10 Institute for Health Metrics and Evaluation. Global burden of diseases, injuries, and risk factors study 2010 [Internet]. Seattle, Washington; IHME; 2010 [cited 2013 Jan I7].Available from: http:// www.healthmetricsandevaluation.org/gbd/research/project/globalburden-diseases-injuries-and-risk-factors-study-20I0

II Horton R. GBD 2010: understanding disease, injury, and risk. Lancet 20I3; 380:2053-4. http://dx.doi.org/I0.1016/S0 I40-6736(I2)62I33-3

12 Vos T, Flaxman AD, Naghavi $M$ et al. Years lived with disability (YLDs) for II 60 sequelae of 289 diseases and injuries 1990-20I0: a systematic analysis for the GBD Study 2010. Lancet 2013; 380:2 I63-96. http://dx.doi.org//0.I0I6/S0I40-6736(I2)6I729-2

13 Chan M. From new estimates to better data. Lancet 2013; 380:2054. http://dx.doi.org/I0.I0I6/S0I40-6736(I2)62 I35-7

14 World Health Organization. Grand challenges in genomics for public health in developing countries [Internet]. Geneva:WHO; 2013 [cited 2013 Jan 17]. Available from: http://www.who.int/rpc/grand_ challenges.pdt 
I5 European Surveillance of Congenital Abnormalities (EUROCAT) [Internet]. Ulster: EUROCAT [cited 2013 Jan I7]. Available from: http://www.eurocat-network.eu/

16 Orphanet. The portal for rare diseases and orphan drugs [Internet] Paris: Orphanet [cited 2013 Jan 17]. Available from: http://www. orpha.net/

17 Sinha S, Black ML, Agarwal S et al. Thallnd, a $\beta$-thalassemia and hemoglobinopathies database for India: defining a model countryspecific and disease-centric bioinformatics resource. Hum Mutat 201 I; 32:887-93. http://dx.doi.org/10.1002/humu.21510

18 Bellgard MI, Macgregor A, Janon F et al. A modular approach to disease registry design: successful adoption of an internet-based rare disease registry. Hum Mutat 20I2; 33:E2356-66. http://dx.doi. org/10.1002/humu.22154

19 Hamamy H, Bittles AH. Genetic clinics in Arab countries: meeting individual, family and community needs. Public Health Genomics 2009; 12:30-40. http://dx.doi.org//0.1 I59/000/53428

20 Bittles $\mathrm{AH}$. Consanguinity in context. Cambridge: Cambridge University Press; 2012. Available from: www.cambridge. org/9780521781862

21 Qureshi N, Raeburn S. Risks to offspring of consanguineous marriage: we need straight, not crooked thinking.J $R$ Coll Physicians Edinb 20 I I; 4 I: 194-5. http://dx.doi.org/I0.4997/JRCPE.20 I I.30 I
22 Acosta AX, Abé-Sandes K, Giugliani R et al. Delivering genetic education and genetic counselling for rare diseases in rural Brazil.J Genet Counsel 2013. http://dx.doi.org/10.1007/s 10897-013-9570-x

23 Centro de Educacion Medica e Investigaciones clinicas. ECLAMC - Estudio Collaborativo Latinamericano de Malformaciones Congenitas [Internet]. Argentina: CEMIC [cited 2013 Jan 17]. Available from: www.cemic.edu.ar/investigacion/inv_unidadesyprog_eclamc.asp

24 Centre for Arab Genomic Studies. Catalogue for transmission genetics in Arabs [Internet]. Dubai: CAGS [cited 2013 Jan 17]. Available from: http://www.cags.org.ae/ctga_search.html

25 World Health Organization. WHO Collaborating Centres global database [Internet]. Geneva:WHO [cited 2013 Jan 17]. Available from: http://apps.who.int/whocc and http://www.who.int/genomics 26 Manolio TA, Collins FS, Cox NJ et al. Finding the missing heritability of complex diseases. Nature 2009; 46I:747-53. http://dx.doi. org/10.1038/nature08494

27 Gonzaga-Jauregui C, Lupski JR, Gibbs RA. Human genome sequencing in health and disease. Ann Rev Med 2012; 63:35-6I. http://dx.doi.org/I0.I I46/annurev-med-05 I010-162644

\section{INVITATION TO SUBMIT PAPERS}

We would like to extend an invitation to all readers of The Journal of the Royal College of Physicians of Edinburgh to contribute original material, especially to the clinical section. The JRCPE is a peer-reviewed journal with a circulation of 8,000 . It is also available open access online. Its aim is to publish a range of clinical, educational and historical material of cross-specialty interest to the College's international membership.

The JRCPE is currently indexed in Medline, Embase, Google Scholar and the Directory of Open Access Journals. The editorial team is keen to continue to improve both the quality of content and its relevance to clinical practice for Fellows and Members. All papers are subject to peer review and our turnaround time for a decision averages only eight weeks.

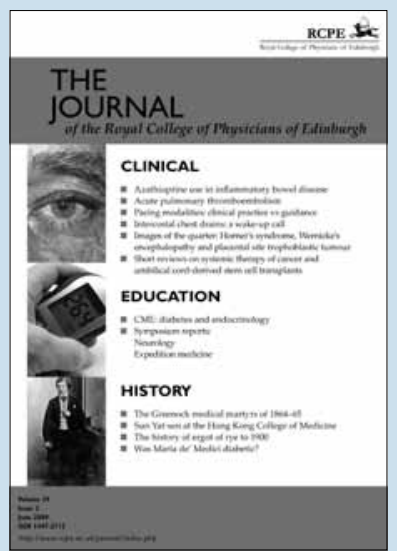

We would be pleased to consider submissions based on original clinical research, including pilot studies. The JRCPE is a particularly good forum for research performed by junior doctors under consultant supervision. We would also consider clinical audits where the 'loop has been closed' and a demonstrable clinical benefit has resulted.

For further information about submissions, please visit: http://www.rcpe.ac.uk/journal/contributers.php or e-mail editorial@rcpe.ac.uk.Thank you for your interest in the College's journal.

The editorial team,

The Journal of the Royal College of Physicians of Edinburgh 